\title{
Educación ambiental en la escuela secundaria: desde las concepciones previas de los estudiantes, la construcción de un horno solar como práctica educativa ${ }^{1}$
}

\author{
Weslaine da Silva Santos ${ }^{1}$ \\ cfs.weslaine@gmail.com \\ https://orcid.org/0000-0003-0347-7122 \\ Marcelo Franco Leão ${ }^{1}$ \\ marcelo.leao@cfs.ifmt.edu.br \\ https://orcid.org/0000-0002-9184-916X \\ ${ }^{1}$ Instituto Federal de Mato Grosso (IFMT; Confresa, Brasil)
}

Recibido: 13/04/2020 Aceptado: 18/05/2020

\section{Resumen}

La Educación Ambiental (EA) impregna todas las áreas del conocimiento y se puede trabajar de diferentes maneras y en diferentes espacios con el objetivo de contribuir a la formación de las personas para que vivan con el medio ambiente de manera equilibrada y sostenible. El objetivo del estudio fue analizar las percepciones de los estudiantes de una clase de secundaria en una escuela pública en Mato Grosso sobre EA, así como desarrollar una actividad experimental como una acción práctica sostenible. Esta es una investigación descriptiva y exploratoria, con un enfoque cualitativo, realizada en 2019, en una escuela pública en Confresa / MT. En el estudio participaron 21 estudiantes y utilizó cuestionarios abiertos para recopilar datos, aplicados antes y después de la práctica experimental. La actividad práctica consistió en construir y probar un horno solar desarrollado con materiales de bajo costo. Los resultados revelaron las percepciones sobre el concepto de EA y el medio ambiente, los problemas ambientales actuales, la participación en acciones ambientales, la evaluación de la intervención realizada, las contribuciones al pensamiento crítico y el aprendizaje construido. Por lo tanto, la construcción del horno solar fue capaz de sensibilizar a los estudiantes, mostrándoles una práctica fácil, barata y rápida que se puede tomar como una solución a los problemas ambientales.

Palabras clave: Educación ambiental, medio ambiente, horno solar.

\section{Educação Ambiental no Ensino Médio: Das concepções prévias dos estudantes a construção de um forno solar como prática educativa}

\section{Resumo}

A Educação Ambiental (EA) perpassa todas as áreas do conhecimento e pode ser trabalhada de diferentes maneiras e diversos espaços visando contribuir na formação de pessoas para que convivam com o ambiente de forma equilibrada e sustentável. O objetivo do estudo foi analisar as percepções dos estudantes de uma turma de Ensino Médio de uma escola pública matogrossense acerca da EA, bem como desenvolver uma atividade experimental como ação prática sustentável. Trata-se de uma pesquisa descritiva e exploratória, com abordagem qualitativa, realizada em 2019, em uma escola pública de Confresa/MT. O estudo envolveu 21 estudantes e utilizou questionários abertos para coletar de dados, aplicados antes e após a prática experimental. A atividade prática consistiu na construção e testagem de um forno solar desenvolvido com materiais de baixo custo. Os resultados revelaram as percepções sobre o

\footnotetext{
${ }^{1}$ Esse estudo contou com auxílio financeiro do Edital 31/2020 da PROPES/IFMT para revisão, formatação e tradução do resumo.
} 
conceito de EA e meio ambiente, problemas ambientais atuais, participação em ações ambientais, avaliação da intervenção realizada, contribuições para o pensamento crítico e aprendizados construídos. Logo, a construção do forno solar foi capaz de sensibilizar os estudantes, demonstrando a estes uma prática fácil, barata e rápida que pode ser tomada como solução para os problemas ambientais.

Palavras-chave: Educação Ambiental, meio ambiente, forno solar.

\title{
Environmental Education in High School: From the students' previous conceptions the construction of a solar oven as an educational practice
}

\begin{abstract}
Environmental Education (EE) permeates all areas of knowledge and can be worked in different ways and in different spaces aiming to contribute to the formation of people so that they live with the environment in a balanced and sustainable way. The aim of the study was to analyze the perceptions of students from a high school class in a public school in Mato Grosso about $\mathrm{EE}$, as well as to develop an experimental activity as a sustainable practical action. This is a descriptive and exploratory research, with a qualitative approach, conducted in 2019, in a public school in Confresa / MT. The study involved 21 students and used open questionnaires to collect data, applied before and after the experimental practice. The practical activity consisted of building and testing a solar oven developed with low-cost materials. The results revealed the perceptions about the concept of EE and the environment, current environmental problems, participation in environmental actions, evaluation of the intervention performed, contributions to critical thinking and constructed learning. Therefore, the construction of the solar oven was able to sensitize students, demonstrating to them an easy, cheap and quick practice that can be taken as a solution to environmental problems.
\end{abstract}

Keywords: Environmental education, environment, solar oven.

\section{Introdução}

Atualmente, o termo Meio Ambiente (MA) e Educação Ambiental (EA) são amplamente utilizados, divulgados e discutidos em escolas. Compreende-se que a EA tenha como principal objetivo formar indivíduos preocupados com os problemas ambientais e que sejam capazes de propor ações de conservação e preservação dos recursos naturais, bem como a sustentabilidade.

Assim, a EA torna-se cada vez mais necessária, especialmente no ambiente escolar, devendo estar presente no processo educativo formal e não formal, em prol de melhorar a qualidade da vida na Terra. Ao sensibilizar a criança e/ou adolescente em fase de formação cognitiva, é possível construir uma estratégia promissora para alcançar novos resultados. Entretanto, a EA não deve ser realizada isoladamente, mas sim como uma parte de um processo educativo contínuo, resultando em práticas transformadoras (Fragoso; Nascimento, 2018). 
Segundo Lopes, Bispo e Carvalho (2009), a EA é efetiva para mudanças no comportamento do ser humano, sendo o período escolar, o momento mais propício para essa inserção, pois será a base da formação de cidadãos conscientes. A sustentabilidade é considerada uma medida de preservação do meio ambiente que busca utilizar a natureza para atender as necessidades da sociedade. Além disso, o desenvolvimento sustentável é utilizado como um modelo econômico que busca conciliar o desenvolvimento econômico à preservação e manutenção de recursos naturais disponíveis.

Os problemas ambientais são diversos, sendo o desenvolvimento sustentável uma forma de minimizar e/ou solucionar tais problemas. A emergência do desenvolvimento sustentável como projeto político e social tem promovido a orientação de esforços como uma forma de encontrar caminhos para uma sociedade sustentável (Sartori; Latronico \& Campos, 2014). Com isso, surge uma quantidade significativa de estudos científicos, sobre o assunto, contudo, causando uma indefinição de foco.

O interesse pela sustentabilidade tem crescido cada vez mais, com a crescentes abordagens estratégicas de uma produção mais limpa, controle da poluição, ecoeficiência, gestão ambiental, responsabilidade social, ecologia industrial, investimentos éticos, economia verde, ecodesign, reuso, consumo sustentável, resíduos zero, entre inúmeros outros termos (Sartori; Latronico \& Campos, 2014).

Diante de todo esse aumento dos problemas ambientais, se mostra a necessidade de se construir medidas que garantam a sustentabilidade ambiental. A partir desse contexto, Abreu et al. (2018) reafirma a escola como um espaço essencial na formação de cidadãos conscientes das questões socioambientais e de sua influência na sustentabilidade.

Dado ao exposto, este estudo teve por objetivo analisar as percepções dos estudantes de uma turma de Ensino Médio da escola 29 de julho, localizada no município de Confresa MT acerca da EA e meios sustentáveis, bem como realizar uma intervenção como uma metodologia experimental de forma a proporcionar uma maior compreensão aos estudantes acerca da importância do relacionamento sensato com o meio ambiente.

\section{Fundamentos teóricos sobre Educação Ambiental}

A palavra meio ambiente foi usada em 1909 pela primeira vez por Jacob Von Uexkull, biólogo e filósofo alemão. Até a primeira metade desse século, as preocupações ambientais eram 
inexistentes, sendo limitado apenas a alguns estudiosos e apreciadores da natureza (Ribeiro, 2009).

Segundo a Resolução N 306, do Conselho Nacional do Meio Ambiente (CONAMA) de 2002, o MA é considerado um conjunto de condições, leis, influência e interação de ordem física, química, biológica, social, cultural e urbanística, que permite, abriga e rege a vida em todas as suas formas. Na International Organization for Standardization (ISO) 14001 de 2004 encontra-se a seguinte definição de meio ambiente: “circunvizinhança em que uma organização opera, incluindo-se ar, água, solo, recursos naturais, flora fauna, seres humanos e suas interrelações."

Segundo Beidack e Lima (2007, apud Belfort, 2012 p. 12).: “Atualmente, a preocupação do homem com a natureza ocupa um lugar significante nas diferentes organizações e no meio científico". Os problemas que o meio ambiente enfrenta diariamente, são consequências da noção e ações dos homens sob a natureza.

A Política Nacional de Educação Ambiental (PNEA) caracteriza a EA como sendo o método pelo qual o homem e a sociedade estabelecem valores sociais, conhecimentos, habilidades, atitudes e competências voltadas à defesa do seu habitat (Brasil, 1999).

Para Gonçalves et al. (2017) é considerada um meio pelo qual a sociedade se apropria de conhecimentos e princípios que guiam suas atitudes a manutenção do MA equilibrado. Para os autores, a EA é uma prática educativa, encontrada para a implantação de atividades com a finalidade de causar impacto positivo no comportamento do ser humano, além de desenvolver o senso de responsabilidade quanto ao meio ambiente e recursos naturais.

Segundo Gayford e Dorion (1994), citado por Sato (1997, p. 81), o termo "Educação Ambiental" foi proposto em 1965, pela Royal Society of London, e se remetia à uma definição mais relacionada com a preservação dos sistemas de vida.

Foi apenas a partir da década de 70 que a EA passou a ser concebida como algo mais abrangente, tanto que a primeira conferência realizada pela Organização das Nações Unidas (ONU) para tratar do ambiente humano em Estocolmo em 1972 colocou o ser humano como principal responsável pelo equilíbrio do planeta (Sato, 1997). Nessa conferência ocorreram debates dos países a respeito da globalização dos problemas ambientais e foi recomendado que se criasse o Programa Internacional de Educação Ambiental (PIEA) (Brasil, 2013). 
Outros marcos importantes foram a Conferência de Belgrado em 1975 que declarou o caráter interdisciplinar da Educação Ambiental (Sato, 1997). E a conferência de Tblisi ocorrida em 1977 que é uma referência para os educadores ambientais em todo o mundo, na qual foi definida como função da educação ambiental criar uma consciência e compreensão dos problemas ambientais e estimular a formação de comportamentos positivos (Tozoni, 2006).

O objetivo da educação ambiental é sensibilizar os indivíduos acerca das questões relacionadas ao MA, adquiridas mediante processo de conscientização. A educação ambiental consegue promover mudanças efetivas sob o comportamento das pessoas (Lopes, Bispo e Carvalho (2009). Dessa forma, deve-se conscientizar a população e transformar o conhecimento em modo de vida, promovendo uma mudança de comportamento nas pessoas com relação a meios adequados de tratamento ao meio ambiente (Carvalho \& Siqueira, 2017).

Para falar da implementação da Educação Ambiental na sociedade, deve-se levar em consideração que não existe apenas um tipo de EA. Em seus estudos, Loureiro (2006) divide a EA em duas vertentes, uma denominada conservadora, comportamentalista ou acrítica e outra definida como crítica, transformadora ou emancipatória. Cabe ressaltar que o autor deixa claro que podem existir nuances que não se encaixam em nenhuma dessas.

A primeira tem uma visão naturalista e conservacionista da crise ambiental. Ela foca apenas em conservar os recursos naturais, por isso tem uma característica despolitizada do fazer ambiental, com pouca problematização dos problemas socioambientais baseando-se apenas na dimensão individual de cada pessoa sem levar em consideração a relação sociedade e natureza (Loureiro, 2006).

A segunda, traz como centro do debate a relação do homem com o meio em que vive e com as demais espécies do planeta, pois tem a cidadania e a participação social como práticas indissociáveis da educação ambiental. Tem por objetivo frisar a politização da problemática ambiental e a entende como sendo complexa e interligada a processos como a produção e consumo, ética, tecnologia e interesses públicos e privados. Busca construir valores que promovam bem-estar público, equidade e solidariedade (Loureiro, 2006).

Para alcançar uma gestão sustentável, o ser humano necessita interagir com o mundo de forma consciente e responsável. A concepção de sustentabilidade pressupõe uma relação de equilíbrio para com o meio ambiente e contribui diretamente com a qualidade de vida da sociedade. A sustentabilidade segundo Silva et al. (2016) significa sustentar, conservar, proteger 
e manter em equilíbrio, dessa forma, é considerada uma técnica que resulta na melhoria da qualidade de vida e simultaneamente na minimização dos impactos ambientais negativos.

A EA para a sustentabilidade segundo Tozoni (2006) é um processo de aprendizagem permanente e que deve ser baseada em ações que respeitam todas as formas de vida e colaboram para a construção de sociedades sustentáveis e ecologicamente equilibradas.

Cartaxo (2018) ressalta que a sustentabilidade é resultado da educação que permite ao homem redefinir o modo como se relaciona com a Terra, com o Universo, com a natureza, com a sociedade e consigo mesmo dentro dos critérios de equilíbrio ecológico. Se trata da capacidade de um indivíduo ou um grupo de se manterem em um meio ambiente suprindo suas necessidades do presente sem interferir nos recursos disponíveis para as gerações futuras.

Mas apesar de estar diretamente relacionada, não se limita apenas a área de meio ambiente, relacionando-se com outros setores da sociedade como educação, economia e cultura. A autora supracitada afirma que a educação para o alcance da sustentabilidade deve estar presente em todas as disciplinas e o seu fim último da sustentabilidade é manter as condições para a continuidade da vida e da própria terra. Nos estudos realizados, a autora concorda com a política nacional de EA sobre a importância e interdisciplinaridade da mesma.

A necessidade de preservar o meio ambiente em que vivemos traz à tona uma questão muito importante: Educar o cidadão para que use as fontes de recursos naturais de forma racional. Dessa forma, é preciso orientar todas as partes da sociedade, desde os primeiros anos de vida, para o consumo consciente dos recursos naturais, bem como a preservação do que a natureza nos oferece (Brasil, 2005).

A EA é de suma importância no ambiente escolar e, portanto, está presente no processo educativo formal e não formal, com o objetivo de melhorar a qualidade de vida na terra. Ao sensibilizar o adolescente e/ou criança que está em formação cognitiva, é possível construir uma estratégia promissora acerca dos cuidados ao meio ambiente. No entanto, a educação ambiental não deve ser realizada de forma isolada, deve fazer parte do processo educativo contínuo (Fragoso \& Nascimento, 2018).

Compreender a relação entre o ser humano e o meio ambiente é o primeiro passo para a sensibilização dos indivíduos acerca de uma mudança de comportamento e conscientização no que concerne aos problemas naturais (Barboza; Brasil \& Conceição, 2016). Os autores relatam que a percepção ambiental se caracteriza por um processo mental de interação da pessoa com o 
ambiente no qual está inserida. Tal processo proporciona a mesma uma visão global de tudo ao seu redor, permitindo um maior envolvimento consigo e com o outro, expondo-se a detalhes e as interligações com o meio biótico e abiótico que a cerca.

Segundo Silva (2010) o papel da escola é de extrema importância, pois é possível conscientizar seus estudantes, levando-os a refletir sobre suas ações no contexto de meio ambiente, bem como realizar um trabalho de forma preventiva, a partir da orientação com a criança e/ou adolescente de forma a torna-lo um adulto diferente do que conhecemos, ou seja, um cidadão mais consciente. Silva (2010) ainda ressalta que se a EA for realizada nas escolas desde o ensino fundamental, é possível tornar pessoas mais conscientes com o meio ambiente e futuramente, este problema será minimizado e a situação ambiental poderá tomar rumos melhores.

No Brasil, a EA passou a ser obrigatória em todas as escolas a partir da Constituição Federal de 1988 que destaca em seu artigo 225 inciso VI que: “a Educação Ambiental deverá ser promovida em todos os níveis de ensino", com a finalidade de conscientizar a população para a preservação e conservação do meio ambiente (Brasil, 1988, p. 64). Assim, a EA passa a ser parte curricular da escola brasileira como um dos temas sociais urgentes que deveriam ser trabalhados de forma transversal e interdisciplinar em todas as disciplinas. Os professores, contudo, passa a inserir o assunto em suas práticas pedagógicas, em prol de formar estudantes autônomos intelectualmente, reflexivos e capazes de desenvolver o pensamento crítico em relação aos problemas ambientais (Da Silva \& Terán, 2018).

A lei 9795 de 27 de abril de 1999 instituiu a política nacional de educação ambiental (PNEA) como sendo um componente permanente e transversal da educação nacional, devendo estar presente em todas as modalidades do processo educativo. Segundo a referida lei, educação ambiental dever ser conceituada como:

Conforme consta na Lei n 9.795, de 27 de abril de 1999:

[...] os processos por meio dos quais o indivíduo e a coletividade constroem valores sociais, conhecimentos, habilidades, atitudes e competências voltadas para a conservação do meio ambiente, bem de uso comum do povo, essencial à sadia qualidade de vida e sua sustentabilidade. (BRASIL, 1999, p. 01) 
Gonçalves et al. (2017) ressaltam que para que a EA se desenvolva diante de uma nova dimensão educacional, os educadores devem transcender o ensino tradicional, envolvendo para isso além da comunidade escolar, as indústrias, sociedade e governantes.

Entretanto, muitas vezes, os espaços escolares e materiais didáticos, não atendem a realidade dos estudantes, ou seja, não oferecem a eles a oportunidade que os façam perceber o meio no qual estão inseridos. Esta ausência pode prejudicar a percepção e compreensão das pessoas em relação aos problemas ambientais. Dessa forma, esses espaços fechados e limitados devem buscar meios de proporcionar aos estudantes a compreensão do meio natural e antrópico (Barboza; Brasil \& Conceição, 2016).

Nesse contexto a educação ambiental que promove autonomia na construção de conhecimentos se mostra eficaz na implementação da EA nas escolas. Kondrat e Maciel (2013) destacam a importância de que o processo educativo forme pessoas ativas e sensíveis, e que sintam parte de sua responsabilidade nas mudanças atuais pelas quais passa o planeta.

A realização de aulas participativas, são de suma importância para a construção do conhecimento significativo. Um exemplo é a construção de fornos solares, que se dá em equipe e dividida em etapas, podendo ser usada tanto em espaços formais como não formais de educação (De Oliveira; Palheta \& Seabra, 2017).

Fornos solares ou também chamados de concentradores solares, são equipamentos que por serem construídos com espelhos côncavos ou planos, concentram para um determinado ponto a luz solar que neles incide. A concentração da luz solar, provoca um aumento significativo na intensidade da radiação, fazendo com que um objeto ou substância atinja altas temperaturas quando ali colocado. Tais concentradores podem ser utilizados na cocção de alimentos e esterilização de água, apresentando ainda diversos benefícios como: conservação de combustíveis convencionais como lenha e em consequência, a preservação do ecossistema (De Oliveira; Palheta \& Seabra, 2017).

Segundo Chianca (2019):

O emprego dos fornos solares pode ser uma solução econômica e ambiental para amenizar a situação de vida da população de baixa renda, pois o uso do gás de cozinha é de alto custo. Além disso, algumas regiões do país existe a dificuldade de compra do gás, por serem áreas afastadas e de difícil acesso. O forno solar pode ser uma alternativa para assar os alimentos sem que se utilize a lenha, gás de cozinha ou até mesmo a energia elétrica, fazendo com que a utilização dos 
combustíveis não renováveis ficasse restritos a dias chuvosos, dias com pouca luz do sol e a noite. (CHIANCA, 2019, p.3):

O forno solar ainda não é considerado uma das formas convencionais de cozinhar, mas pode ser usado como uma alternativa econômica em casa.

No estudo desenvolvido por Sarmento (2015), fica evidente que existem três tipos de forno solar, o forno parabólico, o forno estilo caixa e o forno estilo painel, ambos podem ser construídos usando materiais simples e de baixo custo e se utiliza da luz solar para aquecimento. Eles consistem em espelhos que concentram a luz solar em um determinado ponto, provocando um aumento na intensidade da radiação de modo que a substância (objeto, alimento) ali presente atinja altas temperaturas.

$\mathrm{O}$ uso desses equipamentos para fins educativos pode servir para trabalhar diversos temas, a exemplo da pesquisa de Gallego et. al (2014), que foi desenvolvida com uma turma de estudantes de $6^{\circ}$ ano da cidade de Cascavel/PR. Foi usado a construção de um forno solar para abordar os temas tecnologias sociais, utilização de energias renováveis e efeito estufa, todos pertinentes a EA e conteúdos científicos como radiação solar, transformação de energia, ciclo da água entre outros.

A EA pode ser construída em diversos espaços, a exemplo disso tem-se a pesquisa de Silva e Ruffino (2016), que foi desenvolvida com os participantes do projeto Flor da idade, flor da cidade em Itirapina/SP. Eles fizeram 14 encontros com os participantes do projeto, que recebiam aulas de capoeira e futebol e realizavam o plantio de mudas e hortaliças em uma unidade de conservação da cidade. Nesses encontros foram abordados o tema da conservação da biodiversidade de maneira prática e lúdica seguindo a tendência da EA crítica, além de construírem um material de divulgação sobre o projeto. Como resultado da avaliação da pesquisa percebeu-se que houve aprendizado significativo e coerente com a realidade social dos participantes.

\section{Procedimentos Metodológicos}

A presente pesquisa, descritiva e exploratória, ocorreu na escola Estadual 29 de julho, localizada no município de Confresa/MT, distante $1.200 \mathrm{Km}$ de Cuiabá/MT. A abordagem do estudo é qualitativa. Para Gil (2010), essa abordagem de pesquisa possibilita interpretar subjetivamente um fenômeno, situação ou objeto eleito para ser investigado, pois considera a 
situação estudada de maneira a perceber ao mesmo tempo as individualidades e os significados múltiplos.

A pesquisa foi desenvolvida no período de julho a dezembro de 2019 , e se dividiu em quatro etapas: análise bibliográfica (leitura de artigos para fundamentação teórica), aplicação de um questionário inicial para conhecimento das percepções dos estudantes de uma turma do primeiro ano do ensino médio, elaboração de uma atividade prática e aplicação de um outro questionário avaliando a intervenção realizada.

Essa intervenção pedagógica foi desenvolvida com a turma do $1^{\circ}$ ano $\mathrm{H}$ do Ensino Médio, turno vespertino, durante as aulas de biologia. Essa turma possui um total de 21 estudantes com idade entre 15 e 16 anos, sendo que 11 meninas e 10 meninos. A escolha dessa turma se deu, devido ao interesse de se conhecer a percepção dos estudantes e consequentemente conhecer como a EA foi trabalhada com esses durante o Ensino Fundamental, a partir do conhecimento de quais ações de EA eles participaram durante essa fase do ensino. Além disso, visava contribuir para a formação dos participantes da pesquisa e aproximá-los do tema trabalhado já no primeiro ano do Ensino Médio, etapa de início de uma nova fase da vida escolar.

Como a pesquisa foi desenvolvida em sala e durante quatro semanas nas aulas de biologia, a participação não foi optativa, porém todos foram previamente informados dos objetivos e procedimentos que seriam realizados, além da proposta ter recebido autorização da gestão da escola que emitiu Carta de Anuência. Os estudantes se interessaram pelo projeto pois tinham o desejo de guardar o material produzido para uso no futuro.

A primeira etapa da pesquisa foi realizada durante quatro meses no período de agosto a novembro de 2019. Consistiu em uma revisão bibliográfica da produção científica que aborda ações de educação ambiental no ensino médio nos anos (2014, 2015, 2016, 2017, 2018 e 2019) tendo como bases livros, publicações em revistas científicas, e, teses de graduação, mestrado e doutorado disponíveis na Scielo Brasil e no Periódicos Capes.

A segunda etapa da pesquisa ocorreu durante as aulas de biologia na segunda semana de outubro. Foi aplicado o questionário 1, constituído por 7 questões abertas e respondido por 18 estudantes. As perguntas foram entorno do conceito de EA e MA, reflexões sobre a exploração dos recursos naturais, problemas ambientais enfrentados atualmente e atividades que caracterizam ações de EA. Nesse questionário os sujeitos pesquisados responderam questões 
sobre o conceito de meio ambiente e educação ambiental, problemas ambientais e ações de conservação ao meio ambiente. Embasados em seus conhecimentos prévios.

Após terminarem de responder o questionário, foi apresentada a ideia de construção e teste do forno solar e de todo o projeto de pesquisa. Mostrei um forno já pronto construído previamente para este fim e falei sobre as diferentes formas de obtenção de energia e sobre a aplicabilidade do forno. Combinei de começar essa atividade na semana seguinte e eles se propuseram a fornecer alguns materiais como cola, estilete, tesoura e pincel que poderiam levar de casa.

A terceira etapa foi a elaboração de uma ação de intervenção em educação ambiental voltada a estudantes do Ensino Médio e que teve o objetivo de proporcionar aos estudantes uma maior compreensão da importância do relacionamento sensato com o ambiente. Essa parte da pesquisa ocorreu durante 2 semanas do mês de outubro durante as aulas de biologia e consistiu na construção e teste do forno solar estilo caixa. Foi escolhida essa prática por ser um modelo fácil de fazer, podendo ser utilizados materiais de baixo custo e servindo como material didático de fácil trabalho interdisciplinar e que poderia ficar na escola para ser aproveitado em aulas posteriores. O desenvolvimento dessa pesquisa corroborou com o assunto trabalhado em sala de aula: consumo, conservação e sustentabilidade.

No primeiro momento foi levado um forno solar já pronto que foi usado para demonstração e explicado alguns conceitos físicos envolvidos em seu funcionamento. Foram apresentados alguns conceitos a respeito da energia solar e dos impactos socioambientais resultantes da exploração de fontes não renováveis de energia.

Na sequência foi explicado sobre a aplicabilidade do forno, principalmente na região de localização da escola que tem uma boa incidência solar e também sobre como ele serve principalmente para famílias de localidades isoladas e sem acesso a eletricidade como alternativa ao uso de madeira durante a cocção de alimentos pois essa prática, que ocorre principalmente em áreas de zona rural liberam gases poluentes e afetam a saúde das pessoas. Nesse momento alguns estudantes falaram que o forno poderia ser usado em fazenda e também em acampamentos. Ainda foi abordado sobre o baixo custo de produção do forno que pode ser feito com materiais de reuso.

Para a construção do forno com a turma, essa foi organizada em círculo e os materiais que seriam usados na construção do forno foram colocados em uma mesa no centro do círculo. 
Os materiais usados para a construção foram: 1 caixa de papelão $(32 / 30 \mathrm{~cm})$ e 1 caixa de papelão $(34 / 31 \mathrm{~cm})$, várias placas de papelão, 3 placas de isopor, alguns pedaços de isopor, 1 pedaços de vidro, 1 colas de isopor, 1 cola tecbond $® \mathrm{n}^{\circ} 3,1$ tinta para tecido preta, pincel, tesoura, estilete, régua e 1 rolo de papel alumínio. O papelão o vidro e o isopor foram reaproveitados. O papel alumínio, a tinta e a cola tecbond ${ }^{\circledR} \mathrm{n}^{\circ} 3$, foram comprados e os demais materiais foram fornecidos pelos estudantes.

Foi explicada a funcionalidade de cada material a ser usado: caixa externa com a função de servir de proteção e acoplar tudo o que for inserido no interior do forno, caixa interna $2 \mathrm{~cm}$ menor em comprimento e em altura que a externa, pedaços de papelão e isopor (ou qualquer outro material que sirva como isolante térmico) para isolar a temperatura no interior do forno, aba refletora a ser feita de papel alumínio com o objetivo de direcionar a luz para dentro do forno, tinta preta para pintar a parte externa e ajudar na absorção da luz e tampa feita de vidro para impedir a perda de temperatura para o ambiente.

Em seguida se iniciou a construção do forno. Para isso os estudantes foram divididos em grupos de 3 a 4 integrantes e uma estudante ficou responsável por fotografar todo o processo. A divisão de grupos se deu apenas para organização de cada etapa do trabalho, mas os estudantes ficaram livres para transitar entre as tarefas que preferissem fazer.

Um grupo de estudantes ficou responsável por pintar e fazer a colagem do fundo para maior firmeza e dar estrutura para a caixa externa. A pintura do fundo da caixa interna foi responsabilidade de outro grupo. Bem como o corte das placas de papelão que serviriam como isolante térmico foi feita por um grupo diferente e outro grupo foi responsável por preparar as placas de isopor que serviriam também como isolante e o pedaço de isopor onde o pedaço de vidro seria fixado para servir como tampa. Enquanto isso, um grupo de estudantes preparava a aba refletora que consistiu em um pedaço de papelão com as medidas $30 \mathrm{~cm}$ por $26 \mathrm{~cm}$ revestido de papel alumínio.

Após a pintura do fundo da caixa interna, ela foi revestida nas laterais com papel alumínio, percebemos que era mais eficiente cortar o papel alumínio já do tamanho adequado e colá-lo com cola de isopor, para evitar rasgos e desperdício.

Após todo esse trabalho em equipes separadas, todas as partes preparadas foram colocadas juntas em cima da mesa para montagem do forno. $\mathrm{O}$ passo inicial foi colocar a placa de isopor que ficaria no fundo da caixa externa e fixar a caixa interna em cima dela, isso foi 
feito com auxílio de cola de isopor. Em seguida foi colocado as 2 placas de isopor entre as caixas e os outros dois lados foram preenchidos com as placas de papelão, lembrando que algumas placas de papelão ficaram desiguais, então elas foram cortadas novamente com estilete na hora da montagem até ficar com a altura ideal (Figura 1).

Figura 1: Momentos da construção do forno solar.

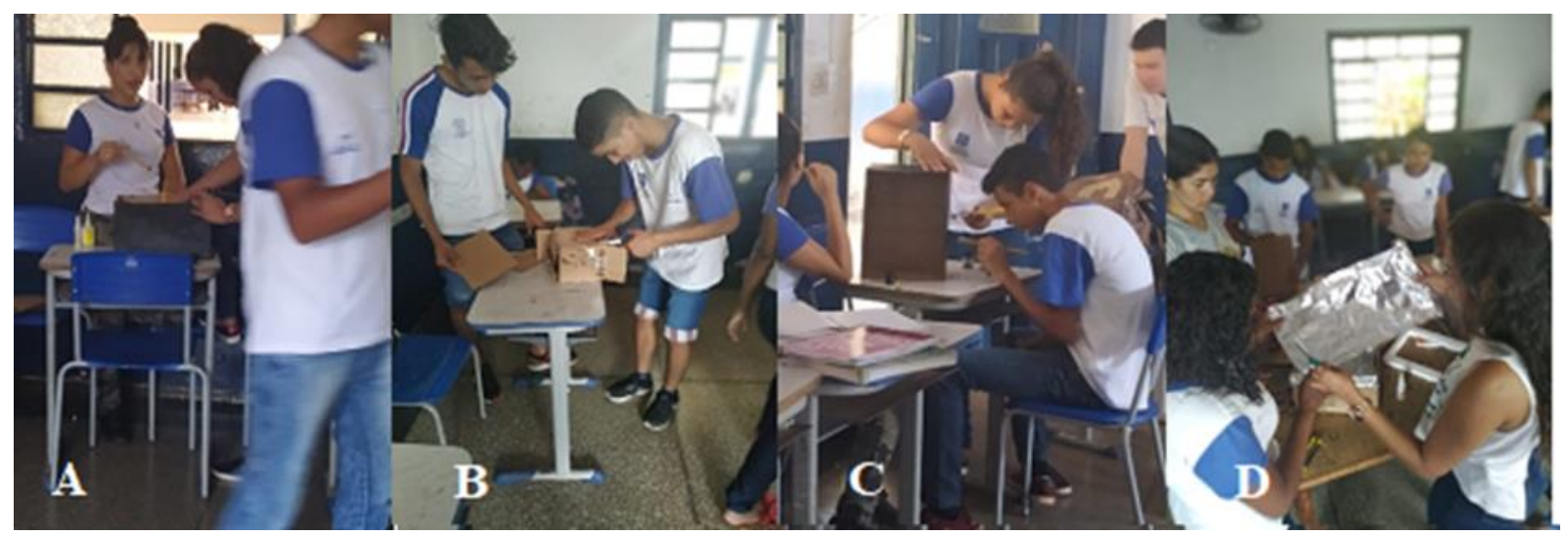

Fonte: Acervo pessoal de W. S. S. (2019).

Após preenchidos todos esses espaços, foi construída a tampa do forno usando o pedaço de vidro e o isopor preparado previamente, o vidro foi fixado no isopor usando cola de isopor e o tempo de espera para efeito de secagem da cola foi de 10 minutos. Após colocada a tampa do forno, anexou-se a aba refletora concluindo assim a construção. A parte final dessa aula foi a organização da sala e recolhimento dos resíduos.

Para testar os fornos solares, cozinhamos um pacote de macarrão instantâneo e também colocamos um pedaço de queijo muçarela para derreter. O sol não estava tão forte, mas os fornos funcionaram mesmo assim. Após 1 hora e 30 minutos o queijo havia começado a derreter e o macarrão miojo estava cozido. Na hora de olharmos os resultados do experimento concluímos que o cozimento do macarrão miojo foi mais eficiente pois este estava dentro de uma panela de cor preta o que potencializou a absorção de calor, já o queijo estava em uma panela aberta. A Figura 2 ilustra momentos da utilização do forno solar. 
Figura 2: Teste realizados com os fornos.

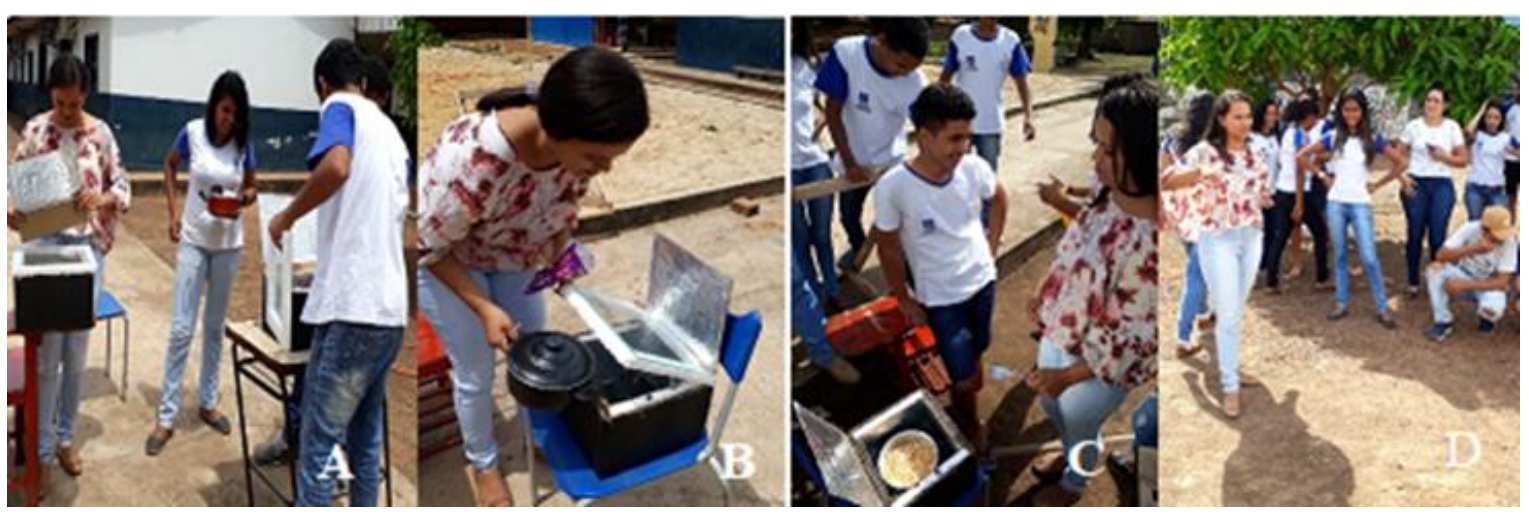

Fonte: Acervo pessoal de W. S. S. (2019).

Durante esse momento da intervenção nós relembramos as vantagens e desvantagens do forno solar e os conceitos que envolvem o seu funcionamento, foi um momento ao ar livre e muito interativo. Os fornos ainda foram testados em um horário diferente do horário das aulas disponibilizadas para o desenvolvimento da pesquisa (das 11h às 13h) com o sol mais forte para comparar com os resultados do teste anterior e, como esperado, funcionou de forma eficiente.

A última fase dessa pesquisa foi a aplicação de um outro questionário para identificar quais aprendizados a atividade proporcionou. Esse instrumento foi constituído por 7 perguntas abertas que investigaram como os estudantes avaliaram a atividade, aprendizados proporcionados, pontos mais significativos, contribuição para a criticidade e posicionamento ambiental.

Para garantir o anonimato dos sujeitos da pesquisa os nomes foram substituídos por símbolos alfanuméricos da seguinte maneira: E1 (estudante 1), E2 (estudante 2), E3 (estudante 3) e assim sucessivamente.

A análise dos questionários foi feita a partir da proposta de Bardin (2012), método conhecido como Análise de Conteúdo. A autora propõe a categorização e subcategorização de respostas a partir do agrupamento de mensagens semelhantes afim de se retirar da palavra dos participantes da pesquisa as mensagens relacionadas ao assunto em estudo. Além disso foi feita a discussão com o aporte teórico disponível na literatura.

\section{Resultados e Discussões}

Inicialmente foi aplicado um questionário com o objetivo de verificar as concepções prévias dos estudantes acerca do tema da pesquisa, bem como determinar se os mesmos já 
haviam participado de atividades relacionadas a EA no Ensino Fundamental. Os resultados obtidos foram agrupados nas seguintes categorias: Conceito de EA e MA; Participação em Ações de Educação Ambiental; Problemas ambientais atuais; e, Contribuições para a formação do pensamento crítico.

Na categoria Conceito de Educação Ambiental e Meio Ambiente foi feita a análise da pergunta 1 "O que você entende por Educação Ambiental?" e da pergunta 2 "O que você entende por meio ambiente?". As respostas foram divididas em duas subcategorias, como pode ser observado no quadro 1.

Quadro 1: Conceito de Educação Ambiental e Meio Ambiente pelos estudantes.

\begin{tabular}{|c|c|c|c|}
\hline \multicolumn{2}{|c|}{$\begin{array}{l}\text { Subcategoria 1: ambiente natural, não } \\
\text { modificado pelo ser humano. }\end{array}$} & \multicolumn{2}{|c|}{ Subcategoria 2: equilíbrio e sustentabilidade. } \\
\hline $\mathbf{E 3}$ & $\begin{array}{l}\text { "a educação ambiental é uma forma de } \\
\text { sabermos sobre o meio ambiente, de } \\
\text { estudarmos sobre a natureza }\end{array}$ & E1 & $\begin{array}{l}\text { "é o estudo que traz informações sobre a } \\
\text { conservação do ambiente natural e do } \\
\text { modificado pelo homem, com o interesse } \\
\text { de se manter um equilíbrio. É todo o meio } \\
\text { que nos cerca, o ar, a terra, a água, a fauna } \\
\text { e a flora." }\end{array}$ \\
\hline $\mathbf{E 5}$ & $\begin{array}{l}\text { "é a natureza, o lugar onde tem as } \\
\text { árvores, os animais e outros seres vivos." }\end{array}$ & E7 & $\begin{array}{l}\text { "é onde aprendemos a como nos } \\
\text { desenvolvermos no meio em que } \\
\text { vivemos, sem desgastar tudo." }\end{array}$ \\
\hline
\end{tabular}

Fonte: Dados coletados na pesquisa (2019).

A primeira subcategoria observada foi relacionando a EA e o conceito de MA a fauna e flora, como algo que deve ser conservado, mas sem muita aproximação pessoal. A segunda subcategoria observada mostrou aproximação pessoal, relacionando os temas a conscientização do ser humano a respeito do meio em que vive.

A EA é um processo educativo que visa formar cidadãos preocupados com os problemas ambientais. No momento histórico que estamos vivendo, preocupações com a diversidade e complexidade das transformações do planeta, ameaças e riscos socioambientais é cada vez mais necessária. Nesse contexto, segundo Cuba (2010), a escola é um espaço para conectar o estudante com o MA, possibilitando condições e alternativas que estimulem os estudantes a serem conscientes e responsáveis com suas ações com o MA, e, principalmente perceberem-se como um integrante e dependente do meio em que vivem.

A educação e a escola são importantes para sistematizar e socializar o conhecimento dos estudantes, no entanto, os conceitos ambientais não devem ser apenas discutidos em sala de 
aulas, devem ser ampliados para a prática buscando soluções e/ou alternativas sustentáveis como o forno solar.

A segunda categoria partiu do levantamento de ações de EA que já haviam participado ao longo do Ensino Fundamental e dos primeiros semestres do $1^{\circ}$ ano, além de atividades fora da escola. Envolveu as perguntas 3 "Em suas aulas, já ocorreram atividades que te levaram a refletir sobre a exploração dos recursos naturais?" e 6 "Cite exemplos de atividades que caracterizam ações de educação ambiental.” do questionário. No Quadro 2 é possível verificar algumas respostas que caracterizam as subcategorias.

Quadro 2: Participação dos estudantes em ações de Educação Ambiental

\begin{tabular}{|c|c|c|c|}
\hline \multicolumn{2}{|c|}{$\begin{array}{l}\text { Subcategoria 1: ações de descarte correto do } \\
\text { lixo. }\end{array}$} & \multicolumn{2}{|c|}{ Subcategoria 2: desmatamento e arborização. } \\
\hline E8 & $\begin{array}{l}\text { "limpeza urbana e descarte correto do } \\
\text { lixo." }\end{array}$ & E5 & $\begin{array}{l}\text { "acho que já participei de algumas } \\
\text { ações. Já plantei árvores e coletei lixo, } \\
\text { reformamos a quadra da escola e a } \\
\text { praça." }\end{array}$ \\
\hline E9 & $\begin{array}{l}\text { "sobre o lixo jogado em qualquer lugar e } \\
\text { nos rios." }\end{array}$ & E17 & $\begin{array}{l}\text { "plantar árvores e reciclar os } \\
\text { materiais". }\end{array}$ \\
\hline \multicolumn{2}{|c|}{$\begin{array}{l}\text { Subcategoria 3: Preservação dos recursos } \\
\text { naturais. Para ilustrar trago as respostas do } \\
\text { sujeito E15 para as perguntas } 3 \text { e } 6 \text {, } \\
\text { respectivamente. }\end{array}$} & \multicolumn{2}{|c|}{$\begin{array}{l}\text { Subcategoria 4: Sociologia. Exemplificada nas } \\
\text { respostas que se seguem: }\end{array}$} \\
\hline E15 & $\begin{array}{l}\text { "Sim, sobre a exploração dos animais, as } \\
\text { plantas, as árvores e rios." }\end{array}$ & E1 & $\begin{array}{l}\text { "sim. Sobre as leis que foram impostas } \\
\text { para a mitigação da degradação } \\
\text { ambiental, durante as aulas de } \\
\text { sociologia." }\end{array}$ \\
\hline E15 & $\begin{array}{l}\text { "preservação de áreas, não queimar, não } \\
\text { desmatar e fiscalização da pesca ilegal." }\end{array}$ & E16 & "Sim, nas aulas de sociologia." \\
\hline
\end{tabular}

Fonte: Dados coletados na pesquisa (2019).

Observou-se que alguns estudantes apesar de já terem participado de algumas ações tinham dúvidas se realmente essa havia sido uma ação de educação ambiental. O que leva a pensar que o tema não foi trabalhado de forma contínua durante o Ensino Fundamental.

Foi perceptível que muitos estudantes não tiveram atividades práticas e interdisciplinares de EA, mas eles mencionaram assuntos trabalhados isoladamente em algumas disciplinas. Foram mencionadas as disciplinas de ciências, geografia e sociologia e enquanto respondiam aos comentários eles falavam sobre o que "a professora falou" se referindo a professora regente de biologia que estava em sala. Isso deixou implícito que muitos estudantes 
não tiveram atividades de EA no Ensino Fundamental, mas que sabiam identificar algumas ações individuais ou em conjunto tanto de prevenção de problemas ambientais como de mitigação de problemas já ocorridos.

A terceira Categoria de análise foi sobre o que os estudantes identificam como problemas ambientais. Baseada nas respostas da pergunta 5 "Quais são os problemas ambientais que enfrentamos atualmente?”. Algumas respostas estão presentes no Quadro 3.

Quadro 3: Problemas ambientais atuais.

\begin{tabular}{|l|l|l|l|}
\hline Subcategoria 1: desmatamento e queimada. & \multicolumn{2}{|c|}{ Subcategoria 2: descarte incorreto de resíduos. } \\
\hline E16 & $\begin{array}{l}\text { "Queimadas e desmatamento." } \\
\text { E18 }\end{array}$ & $\begin{array}{l}\text { "desmatamento, acúmulo de lixo nos } \\
\text { meios urbanos, poluição dos rios e } \\
\text { mares". }\end{array}$ \\
\hline $\begin{array}{l}\text { "Queimadas, poluição e } \\
\text { desmatamento." } \\
\text { Subcategoria 3: esgotamento de recursos devido ao consumo desenfreado. }\end{array}$ & E4 & $\begin{array}{l}\text { "fumaça por causa das queimadas, lixo na } \\
\text { rua, o lixão da cidade de Confresa." }\end{array}$ \\
\hline E6 & $\begin{array}{l}\text { "esgotamento dos recursos e } \\
\text { poluição." }\end{array}$ & $\mathbf{E 1 7}$ & $\begin{array}{l}\text { "desmatamento, alto consumo de energia } \\
\text { e de água." }\end{array}$ \\
\hline
\end{tabular}

Fonte: Dados coletados na pesquisa (2019).

Os resultados obtidos sobre o conhecimento dos estudantes a respeito dos problemas ambientais, mostrou que apesar de a pergunta ter sido aberta a maioria respondeu de acordo com a realidade do local onde vivem. Mencionaram problemas que são facilmente observáveis no cotidiano como pode ser visualizado nas subcategorias 1 e 2 principalmente, quanto ao desmatamento, e, os problemas mais difíceis de serem observados diariamente como os presentes na subcategoria 3 foram pouco mencionados.

A cidade de Confresa/MT, como relatado por Sousa et al. (2013), não possui uma cooperativa de coleta de lixo apesar de, a prefeitura coletar mensalmente o montante de 210,000Kg de resíduos sólidos sendo que desse total apenas $85.000 \mathrm{Kg}$, de ferro, plástico e papelão eram vendidos a um comerciante de materiais reciclados diretamente pelos catadores e todo o resto de resíduos descartados a céu aberto no lixão. Essa realidade pode ser observada na resposta do E4 (estudante 4) presente na categoria 3.

O desmatamento e as queimadas são outros problemas ambientais recorrentes na região. Araújo, Santos e Aragão (2018) demonstram em seu estudo que Confresa/MT está no 
décimo quinto lugar no ranking de desmatamento entre 141 municípios do estado de Mato Grosso, com um total de $3864.5 \mathrm{Km}^{2}$ em área desmatada.

Nota-se que o desmatamento e as queimadas são mencionados juntos em algumas respostas, demonstrando que os estudantes consideram uma ligação entre esses dois fenômenos. De fato, os dois fenômenos estão interligados entre si, o fogo é utilizado tradicionalmente na agricultura e na pecuária para o manejo e preparo do solo, pois é considerado um meio alternativo barato, acessível mesmo em áreas remotas, além de não demandar de tecnologia ou maquinaria. Entretanto, o emprego de fogo em áreas de vegetação é proibido, mas é passível de exceção em algumas circunstâncias.

Segundo o artigo 38 do Código Florestal brasileiro (Lei no 12.651/2012): "I - em locais ou regiões que justifiquem o emprego do fogo em práticas agropastoris ou florestais, mediante prévia aprovação do órgão estadual ambiental." Dessa forma, dentro das normas legislativas e pequena escala, o uso de fogo é legal, pois a prática possibilita retorno da floresta após o cultivo.

Em contrapartida a subcategoria com menor repetição de respostas foi a 3. Ficou evidente que apesar de a demanda energética ser um dos principais contribuintes para as alterações climáticas esse não é um assunto muito presente para os estudantes.

Como aludido por Braga (2012), no contexto atual, que a sociedade industrializada demanda cada vez mais recursos e energia, utilizando como principal fonte o petróleo, um recurso finito e cuja exploração é uma relevante emissora de gases de efeito estufa (GEE) na atmosfera, faz se necessário estudar as formas de aproveitamento de energia a partir de fontes renováveis. Apesar de o alto consumo de energia e esgotamento de recursos como a água terem sido pouco mencionados eles podem estar relacionados ao desmatamento uma categoria bastante lembrada pelos estudantes, devido ao fato de a madeira ainda ser usada como fonte de energia em diversas regiões do globo.

Segundo Brito (2007), o uso da madeira para energia, no contexto mundial, se evidencia nos países em desenvolvimento, sendo que no Brasil o uso da madeira se dá principalmente para a produção de carvão vegetal e em seguida no uso residencial para cocção de alimentos e para aquecer ambientes. $\mathrm{O}$ autor ainda menciona que pelo menos 30 milhões de pessoas depende de madeira para produção de energia domiciliar no Brasil, geralmente pessoas com dificuldades de acesso a outras fontes energéticas por razões socioeconômicas. 
Carvalho (2014) ressalta que mesmo que a madeira seja um combustível potencialmente renovável, a tecnologia utilizada para aproveitá-la em larga escala - a silvicultura - ficou estagnada, além disso, o petróleo e o gás natural não são combustíveis renováveis, de modo que as principais fontes energéticas atuais são insustentáveis. Nesse contexto de exploração energética que geram importantes impactos no meio ambiente cabe a necessidade de ensino sobre esses impactos e a respeito das diferentes formas de aproveitamento de energias que são sustentáveis, para que os estudantes tenham conhecimento da importância desse assunto no contexto do tema tratado.

Um dos objetivos foi entender tudo o que já contribuiu para a formação das concepções que os estudantes possuíam. A análise foi embasada nas respostas das perguntas 4 "Já foi levado(a) a pensar sobre algum problema ambiental e desafiado a se posicionar/solucionar esse problema? Descreva a situação." e 7 "Já participou de atividades que te levou a pensar sobre os diferentes métodos de produção de energia? Descreva."

Para alcançar este objetivo foi feita esta categoria de análise que se dividiu em três subcategorias. A maioria dos estudantes afirmaram não se lembrar ou nunca ter participado desse tipo de atividade, no entanto, ressaltaram o desejo por atividades diferenciadas (Quadro 4).

Quadro 4: Contribuições para a formação do pensamento crítico

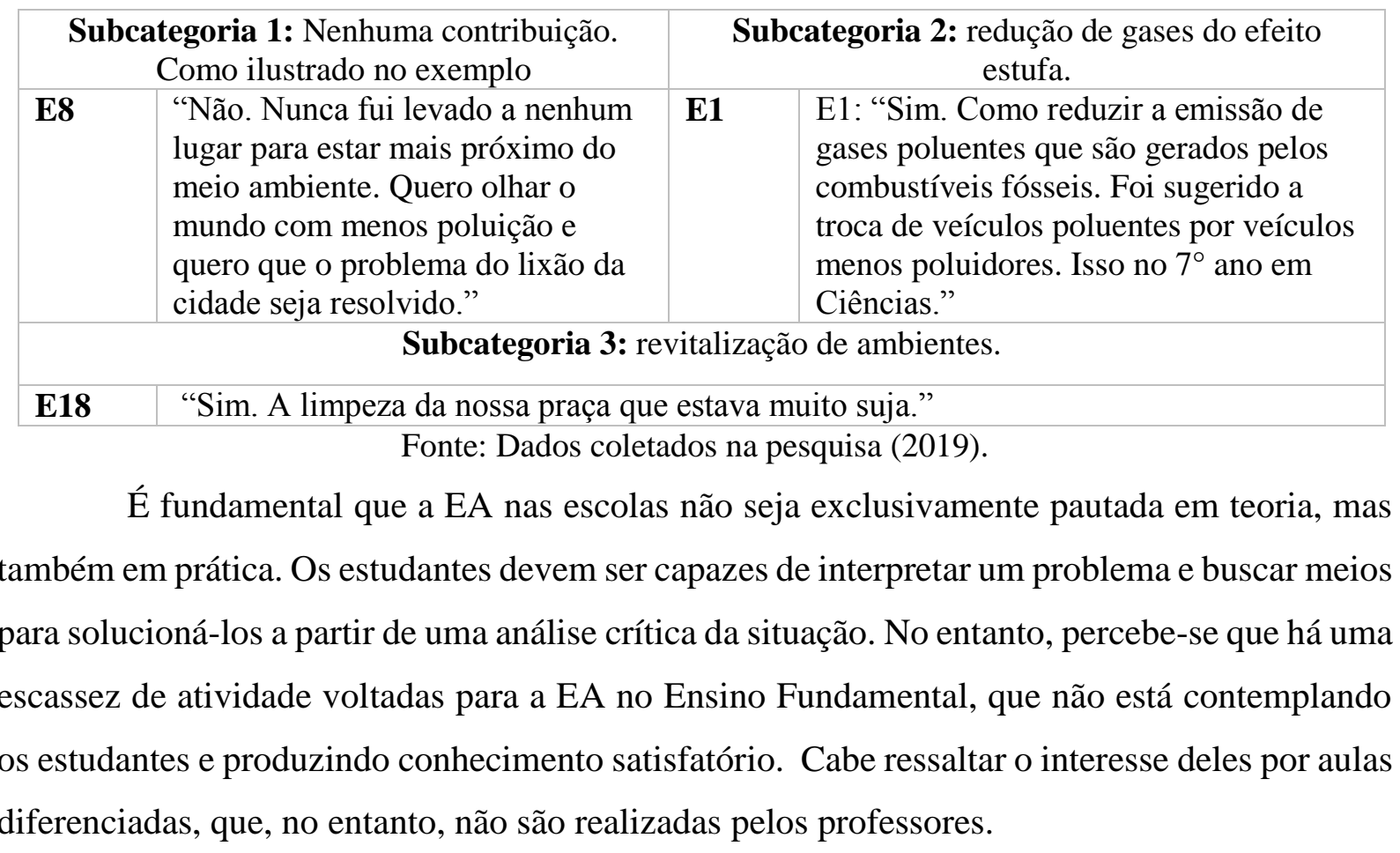


O objetivo do questionário 2 foi avaliar a ação educativa e identificar se ela contribuiu para a formação dos estudantes. Além de saber o que eles acharam mais relevante na atividade.

Esse questionário foi respondido por 14 estudantes que haviam participado das atividades. Das respostas foram identificadas as seguintes categorias: Contribuições para o pensamento crítico; Aplicabilidade do conhecimento adquirido; Principais aspectos observados; e, Construção do aprendizado.

Para saber se a atividade contribuiu para a reflexão e formação do pensamento crítico analisou-se as respostas às perguntas 1 "você considera que essa atividade desenvolvida te levou a refletir sobre os problemas ambientais? Justifique." e 7 "a atividade favoreceu seu senso crítico sobre as problemáticas ambientais? Em que sentido?” do questionário e procurou-se identificar subcategorias das respostas (Quadro 5).

Quadro 5: Contribuições para o pensamento crítico

\begin{tabular}{|c|c|c|c|}
\hline \multicolumn{2}{|r|}{ Subcategoria 1: economia de energia. } & \multicolumn{2}{|c|}{$\begin{array}{l}\text { Subcategoria 2: emissão de gases do efeito } \\
\text { estufa. }\end{array}$} \\
\hline E6 & $\begin{array}{l}\text { "sim, foi uma forma para aprendermos } \\
\text { a economizar energia e porque } \\
\text { reutilizamos os objetos para fazer uma } \\
\text { coisa nova." }\end{array}$ & E14 & $\begin{array}{l}\text { "Sim. Porque foi feita no fogão que não } \\
\text { utiliza e não tem gás e com isso não } \\
\text { prejudica o meio ambiente." }\end{array}$ \\
\hline & & E11 & $\begin{array}{l}\text { "Sim. Porque não polui a camada de } \\
\text { ozônio." }\end{array}$ \\
\hline \multicolumn{2}{|c|}{$\begin{array}{l}\text { Subcategoria 3: crescimento populacional e } \\
\text { utilização de recursos }\end{array}$} & \multicolumn{2}{|c|}{$\begin{array}{l}\text { Subcategoria 4: combate ao desmatamento e } \\
\text { conservação. Exemplificado nas respostas do } \\
\text { estudante (E5) para as perguntas } 1 \text { e } 7 \\
\text { respectivamente. }\end{array}$} \\
\hline E1 & $\begin{array}{l}\text { "Sim. No sentido de que tudo que os } \\
\text { humanos constroem mesmo que, para } \\
\text { deixar de poluir, se utiliza recursos. } \\
\text { Alguns políticos não possuem } \\
\text { consciência ecológica pois acham que } \\
\text { investimentos em materiais que não } \\
\text { gastam muitos recursos são perda de } \\
\text { tempo ou dinheiro e acabam por não } \\
\text { favorecer o mundo. Muitas casas fazem } \\
\text { uso do gás liquefeito de petróleo o GLP, } \\
\text { imagine o quanto já foi poluído na } \\
\text { atmosfera." }\end{array}$ & E5 & $\begin{array}{l}\text { "sim porque ele incentiva a preservação } \\
\text { das plantas e sobre o quanto elas são } \\
\text { importantes para a sobrevivência dos } \\
\text { seres humanos" }\end{array}$ \\
\hline $\mathbf{E 2}$ & $\begin{array}{l}\text { "Sim porque a população vem cada vez } \\
\text { mais aumentando e prejudicando nosso } \\
\text { planeta. Essa opção tem o sentido de } \\
\text { ajudar as pessoas." }\end{array}$ & E5 & $\begin{array}{l}\text { "No sentido de nós podermos abrir } \\
\text { nossos olhos e começar ajudar o nosso } \\
\text { planeta preservando-o sem poluição e } \\
\text { desperdícios preservação." }\end{array}$ \\
\hline
\end{tabular}

Fonte: Dados coletados na pesquisa (2019). 
As respostas dos estudantes para essa categoria de análise, conversaram com a vertente crítica ou emancipatória da Educação Ambiental que é definida por Loureiro (2006) como a EA que tem a cidadania e a participação social como fundamentais e que tem por objetivo a politização da problemática ambiental. Pois eles não desconsideraram os aspectos socioambientais ao responderem as perguntas. Logo tem-se a ideia de que o desenvolvimento dessa pesquisa contribuiu para a formação do senso crítico dos sujeitos participantes.

Para entender sobre se os sujeitos pesquisados consideravam o conhecimento adquirido aplicável, foi analisado as respostas das perguntas 4 "você acha que poderia aplicar o que aprendeu nessa atividade fora do contexto escolar? Justifique." e 6 "na sua opinião a comunidade deveria ter conhecimento sobre esse assunto? Por que?" do questionário. No Quadro 6 é possível verificar algumas respostas que caracterizam as subcategorias.

Quadro 6: Aplicabilidade do conhecimento adquirido

\begin{tabular}{|c|c|c|c|}
\hline \multicolumn{2}{|c|}{$\begin{array}{l}\text { Subcategoria 1: Compartilhamento de } \\
\text { conhecimento. }\end{array}$} & \multicolumn{2}{|c|}{$\begin{array}{l}\text { Subcategoria 2: sensibilização para a escolha de } \\
\text { alternativas sustentáveis }\end{array}$} \\
\hline E4 & $\begin{array}{l}\text { "sim, nós podíamos ensinar as } \\
\text { pessoas, mostrar o nosso } \\
\text { conhecimento que aprendemos no } \\
\text { dia-a-dia em que estudamos. As } \\
\text { pessoas poderiam conhecer mais o } \\
\text { nosso meio ambiente e o que } \\
\text { fazemos na escola." }\end{array}$ & $\mathbf{E 3}$ & $\begin{array}{l}\text { "sim porque em vez de usar o gás que polui o } \\
\text { meio ambiente podem usar o forno solar." }\end{array}$ \\
\hline E7 & $\begin{array}{l}\text { "sim porque nosso aprendizado tem } \\
\text { que ser compartilhado pelo mundo } \\
\text { para aprender sobre o que fazemos } \\
\text { na escola e para que as pessoas } \\
\text { valorizem." }\end{array}$ & E14 & $\begin{array}{l}\text { "aprendi que pode fazer comida sem poluir o } \\
\text { meio ambiente e a atmosfera. As pessoas } \\
\text { poderiam por comida no forno e ir fazer } \\
\text { outras coisas enquanto a comida ia } \\
\text { cozinhando." }\end{array}$ \\
\hline E9 & $\begin{array}{l}\text { "sim, pois as pessoas poderiam usar } \\
\text { quando faltar gás ou em lugares } \\
\text { isolados que não tem fogão e isso } \\
\text { ajudaria as pessoas." }\end{array}$ & E5 & $\begin{array}{l}\text { "sim porque a atividade levaria a } \\
\text { conscientização para pessoas de fora e não } \\
\text { somente para os alunos, incentivaria a } \\
\text { sociedade mudar de vida em relação do nosso } \\
\text { meio ambiente." }\end{array}$ \\
\hline
\end{tabular}

Fonte: Dados coletados na pesquisa (2019).

Ao fazer análise nesta categoria percebeu-se que todos os estudantes demonstraram que a atividade deveria ser replicada com mais pessoas e o conhecimento compartilhado. $\mathrm{O}$ ambiente escolar é essencial na formação de cidadãos conscientes das questões socioambientais e de sua influência na sustentabilidade (Abreu et al., 2018).

Segundo Effting (2007) a EA ajuda a compreender a existência de uma interdependência econômica, social, política e ecológica, ela proporciona possibilidades de adquirir conhecimentos, atitudes, interesse ativo e as atividades que são necessárias para 
proteger e melhorar o meio ambiente. Além disso, a autora frisa que a escola atua com uma mantenedora e reprodutora de uma cultura que é predatória ao ambiente, ou que se limite a ser somente repassadora de informações.

É necessário que a escola encontre meios efetivos de sensibilizar cada estudante sobre os fenômenos naturais, as ações humanas, e sua consequência para consigo, sua espécie e para os outros seres vivos e meio ambiente, buscando valores que conduzam a uma convivência harmoniosa com o meio ambiente e as demais espécies que habitam o planeta (Effting, 2007). Nota-se nas respostas dos estudantes que além deles aprenderem como funciona a prática experimental realizada, eles sentem a importância de compartilhar com outrem o assunto, buscando conscientizar não somente outros estudantes, mas também a sociedade.

Verificou-se também, quais foram os principais aspectos observados pelos estudantes durante as etapas práticas da pesquisa. A partir da análise das respostas às perguntas 2 "quais aspectos você considerou mais significativo dessa atividade?" e 5 "o que mais lhe chamou atenção durante todo o processo de construção e teste do forno solar?" do questionário, divididas nas subcategorias presentes no quadro 7: aproveitamento da energia solar, simplicidade de construção e sustentabilidade.

Quadro 7: Aspectos observados

\begin{tabular}{|c|c|c|c|}
\hline \multicolumn{2}{|r|}{ Subcategoria 1: Aproveitamento da energia solar } & \multicolumn{2}{|r|}{$\begin{array}{c}\text { Subcategoria 2: Simplicidade de } \\
\text { construção }\end{array}$} \\
\hline E1 & $\begin{array}{l}\text { "a utilização do sol, pois ele é uma fonte } \\
\text { inesgotável de energia luminosa e que no forno } \\
\text { foi convertida em calor." }\end{array}$ & $\mathbf{E 3}$ & $\begin{array}{l}\text { E3: "que podemos construir fogões } \\
\text { através de coisas reutilizáveis." }\end{array}$ \\
\hline E6 & $\begin{array}{l}\text { "foi o fato de cozinharmos no sol, isso poderia } \\
\text { ser usado em acampamentos e viagens. o uso } \\
\text { do vidro, o sol bater nele e fazer os alimentos } \\
\text { cozinharem." }\end{array}$ & $\mathbf{E 2}$ & "como foi simples de fazer." \\
\hline E7 & $\begin{array}{l}\text { "o uso do isopor e do vidro e a capacidade de } \\
\text { com o sol cozinhar o miojo." }\end{array}$ & E9 & $\begin{array}{l}\text { "o modo de construção porque foi bem } \\
\text { simples." }\end{array}$ \\
\hline \multicolumn{4}{|c|}{ Subcategoria 3: Sustentabilidade } \\
\hline $\mathbf{E 5}$ & $\begin{array}{l}\text { "Ela foi uma atividade importante que nos fez } \\
\text { compreender mais sobre a importância da vida } \\
\text { na terra e também sobre a preservação do } \\
\text { planeta. que podemos ter alimentos feitos } \\
\text { através da ajuda do sol e não poluindo o nosso } \\
\text { planeta com gases emitidos de fogões elétricos } \\
\text { e nem de fogão à lenha." }\end{array}$ & $\mathbf{E 4}$ & $\begin{array}{l}\text { "Os aspectos observados foram que: } \\
\text { as atividades foram sobre problemas } \\
\text { ambientais e também sobre o lixo na } \\
\text { nossa cidade." }\end{array}$ \\
\hline
\end{tabular}

Fonte: Dados coletados na pesquisa (2019).

A partir desses resultados observou-se que a atividade abordou o tema de forma holística, considerando o fenômeno como um todo. Conforme sugerido por Loureiro (2006), 
que afirma que a EA tem por objetivo frisar a politização da problemática ambiental e a entende como sendo complexa e interligada a processos como a produção e consumo, ética, tecnologia e interesses públicos e privados. Busca construir valores que promovam bem-estar público, equidade e solidariedade.

$\mathrm{Na}$ categoria sobre a construção de aprendizados, foram analisadas as respostas dos sujeitos de pesquisa para a pergunta 3 do questionário "3-Quais os aprendizados proporcionados pela atividade desenvolvida?" Foram identificadas duas subcategorias que estão identificadas no quadro 8 a seguir. No Quadro 8 é possível verificar algumas respostas que caracterizam as subcategorias.

Quadro 8: Construção do aprendizado

\begin{tabular}{|l|l|l|l|}
\hline \multicolumn{2}{|c|}{ Subcategoria 1: Sustentabilidade } & \multicolumn{2}{|c|}{ Subcategoria 2: Construção e funcionamento } \\
\hline E1 & $\begin{array}{l}\text { "tecnologias desenvolvidas para a não } \\
\text { utilização dos derivados de petróleo." }\end{array}$ & $\mathbf{E 4}$ & $\begin{array}{l}\text { "foi um isopor e uma caixa de papelão e } \\
\text { também o vidro depois fizemos uma } \\
\text { aprendizagem construindo um forno e } \\
\text { fizemos teste com ele e deu certo." }\end{array}$ \\
\hline E6 & $\begin{array}{l}\text { "uma forma desenvolvida para } \\
\text { aproveitar energia do sol." }\end{array}$ & $\mathbf{E 3}$ & $\begin{array}{l}\text { "que com energia solar pode fazer coisas } \\
\text { para comer." }\end{array}$ \\
\hline
\end{tabular}

Fonte: Dados coletados na pesquisa (2019).

Percebe-se que a partir da atividade desenvolvida alguns estudantes despertaram mais o seu lado crítico em relação ao desenvolvimento sustentável e de como o objeto construído contribui para o aproveitamento de formas renováveis de energia. Já um outro grupo de estudantes se envolveu mais na parte de construção e funcionamento, levando em consideração o uso da energia solar térmica e de como os materiais usados permitiram o funcionamento do forno.

Concordando com as ideias de, de Oliveira, Palheta e Seabra (2017), já mencionados no referencial teórico constatou-se que a realização dessa atividade participativa e em equipe contribuiu para a construção de conhecimento significativo de forma ampla.

Muitos estudantes acharam interessante o fato de o forno ter sido construído com materiais fáceis de serem encontrados e não precisar de fogo, tanto que, em vários momentos eles falavam sobre o uso do isopor e do papelão como isolantes térmicos. Uma observação feita durante a fase de teste do forno, foi a surpresa de todos ao perceberem que o sol poderia cozinhar os alimentos e como mencionaram poder utilizar o forno construído na feira de ciências e com amigos em acampamentos. 
Percebe-se que não é identificar um problema atual e buscar soluções alternativas para este problema, práticas simples e de fácil execução podem trazer inúmeros benefícios. Durante a prática pode-se observar a curiosidade dos estudantes por estarem experimentando algo novo e colocando em prática. Uma das maiores dificuldades encontradas nas escolas é a abordagem metodológica voltada exclusivamente para a teoria, isso acaba diminuindo o nível de aprendizagem do estudante, pois para ele não é atrativo, não conseguindo despertar um lado crítico, ou seja, ao informá-los de um problema ambiental, eles não seriam capazes de buscar meios para solucionar tal questão.

Antes da atividade notava-se que o conhecimento acerca da EA e problemas inerentes ao meio ambiente eram escassos, além disso, era nítido o desinteresse dos estudantes por esse assunto, as práticas metodológicas não despertavam o interesse. No entanto, ao contextualizar um tema e em seguida aplicá-lo em meio de experimentação e trabalho em equipe com os estudantes, foi possível despertar o interesse além de sensibilizá-los quanto aos problemas ambientais e a importância de ser um cidadão consciente e responsável, bem como o desenvolvimento de um pensamento crítico.

Inicialmente os estudantes não inseriam o contexto social em suas reflexões a respeito do meio ambiente e após a atividade experimental eles passaram a considerar o meio social na discussão sobre meio ambiente demonstrando uma reflexão mais ampla e interesse em divulgação dos aprendizados obtidos com a atividade.

Dessa forma, esse trabalho contribuiu para a formação do pensamento crítico dos estudantes e esteve de acordo com os princípios da Declaração da Conferência Intergovernamental Sobre Educação Ambiental, ocorrida em Tblisi, que é uma referência para os educadores ambientais em todo o mundo e define como função da educação ambiental: criar uma consciência e compreensão dos problemas ambientais e estimular a formação de comportamentos positivos (Tozoni, 2006).

\section{Considerações Finais}

O desenvolvimento dessa pesquisa proporcionou o conhecimento das percepções de estudantes de uma escola do município de Confresa - MT a respeito do tema pesquisado além do conhecimento sobre as ações de educação ambiental das quais participaram no Ensino Fundamental. 
Permitiu aproximação dos estudantes com o tema da EA e das diversas formas de aproveitamento de energia, mostrando algo de fácil construção e facilmente replicável em diversas regiões além da socialização de conhecimentos em aulas interdisciplinares de EA, contribuindo para o cumprimento da PNEA na Escola 29 de Julho.

A EA nas escolas representa um conjunto de ações sustentáveis voltadas para a conservação do MA, ela visa, portanto, o aumento de práticas sustentáveis bem como a redução de danos ambientais por meio da conscientização de cidadãos críticos. Mas, para isso acontecer, é fundamental que a escola se disponibilize a identificar metodologias ativas para ensinar, tal como o desenvolvimento do forno solar como forma de substituir o fogão. Assim como um forno convencional, o forno solar pode desempenhar atividades como assar, grelhar, cozinhar, tostar, desidratar, no entanto, de uma forma economicamente viável e sustentável.

Após o desenvolvimento de todas as etapas da pesquisa e após análise do questionário 2 foi perceptível que os participantes da pesquisa demonstraram não desconsiderar os aspectos sociais envolvidos nas problemáticas ambientais trabalhadas, isso mostra que a atividade desenvolvida contribuiu para o processo de tomada de consciência do papel que o ser humano desempenha no meio em que vive e em como pode influenciar de forma negativa ou positiva o seu entorno.

Percebeu-se a relevância de se trabalhar a EA no primeiro ano do Ensino Médio, fase em que os estudantes estão iniciando essa nova etapa de formação, pois a partir das observações durante todo o desenvolvimento dessa pesquisa e de análise dos questionários 1 e 2 constatouse que ela contribuiu para o empoderamento frente às questões ambientais dos sujeitos participantes e permitiu a construção ativa do conhecimento e sua socialização.

Para além da construção de novos conhecimentos o trabalho contribuiu para a sensibilização dos estudantes a respeito das problemáticas socioambientais e para a construção do pensamento crítico e da importância da socialização do conhecimento adquirido com a comunidade escolar e comunidade externa.

\section{Referências}

Abreu, M. R. M. et al. (2018). Práticas metodológicas para a análise da percepção ambiental dos alunos do IFRN Campus Pau dos Ferros, Rio Grande do Norte, Brasil. Revista GeoTemas. Pau dos Ferros, Brasil, (8) 3, p. 57-79, out./dez. 2018. Disponível em: http://periodicos.uern.br/index.php/geotemas/article/view/3244. Acesso em: 03/09/2019. 
Barboza, L.A.S.; Brasil, D.S.B; Conceição, G.S. (2016). Environmental perception of 6th and 9th grade students from a municipal school in Redenção, Pará State, Brazil/Percepção ambiental dos alunos do $6^{\circ}$ e do $9^{\circ}$ anos de uma escola pública municipal de Redenção, Estado do Pará, Brasil. Rev Pan-Amaz Saude, p. 11-20.

Bardin, L. (2012). Análise de conteúdo. Edições 70. São Paulo.

Belfort, M. R. (2012). Geografia e Educação Ambiental: Uma abordagem introdutória. 2012. p.30. Trabalho de Conclusão de Curso - Departamento de Geografia: Habilitação Bacharel, Universidade Estadual de Londrina. Londrina/PR.

Braga, C.F.G.V.; Braga, L.V. (2012). Desafios da energia no Brasil: panorama regulatório da produção e comercialização do biodiesel. CADERNOS EBAPE.BR. (10) 3, opinião 4. Rio de Janeiro, 751-762.

Brasil (2013). Ministério da Educação. Secretaria de Educação Básica. Diretoria de currículos e educação integral. Diretrizes Curriculares Nacionais Gerais da Educação Básica. Brasília: $\mathrm{MEC} / \mathrm{SEB} / \mathrm{DICEI}$.

Brasil (2002). Resolução Conama $n^{o}$ 306, de 5 de julho de 2002. Estabelece os requisitos mínimos e o termo de referência para realização de auditorias ambientais. Diário Oficial da União, Brasilia, DF, no 138, seção 1, 75-76 Disponível em: <http://www2.mma.gov.br/port/conama/legiabre.cfm?codlegi=306> Acesso em 20 de dezembro de 2019.

Brasil (2004). Norma Brasileira ABNT NBR ISO 14001, de 2004. Sistemas da gestão ambiental Requisitos com orientações para uso. Disponível em: <http://www.madeira.ufpr.br/disciplinasghislaine/iso-14001-2004.pdf> Acesso em: 20 de dezembro de 2019.

Brasil (1999). Lei $n 9.795$ de 27 de abril de 1999. Dispõe sobre a educação ambiental, institui a Política Nacional de Educação Ambiental e dá outras providências. Diário Oficial da União, Brasília, DF. (28).

Brasil (2012). Lei n. 12.651 de 25 de maio de 2012. Dispõe sobre a proteção da vegetação nativa. Diário Oficial da União, Brasília, DF.

Brasil (2005). Ministério do meio ambiente. Manual de Educação para o consumo sustentável, 2005.

https://www.mma.gov.br/estruturas/educamb/_arquivos/consumo_sustentavel.pdf> Acesso em: 05 de fev. 2020.

Brasil (1988). Constituição da República Federativa do Brasil de 1988. Disponível em: < http://www.planalto.gov.br/ccivil_03/constituicao/constituicao.htm> Acesso em: 21 de dezembro de 2019.

Brito, J. O. (2007). O uso energético da madeira. Estudos avançados. São Paulo, (21) 59, 185 193.

Cartaxo, B. R. (2018). Sustentabilidade e educação: papel do cidadão levando-se em consideração as ideias de Amartya Sen. Revista de Direito e Sustentabilidade. Porto Alegre, (4) $2,40-58$.

Carvalho, J. A.; Siqueira, M. N. (2017). A Educação Ambiental como ferramenta na 
conscientização de adolescentes sobre a importância de recuperação de áreas degradadas. Monografia, Faculdade de Engenharia da UniVR. Rio Verde - GO. Junho.

Carvalho, J. F. (2014). Energia e sociedade. Estudos avançados, online (28) 82, 25-39. Disponível em < http://dx.doi.org/10.1590/S0103-40142014000300003>. Acesso em: 05 de fev. 2020.

Chianca, M. S. (2019). Estudo de um forno solar fabricado com gabinetes de computador em desuso. 2019. 95p. Trabalho de Conclusão de Curso (Graduação em Engenharia Mecânica) - Centro de Tecnologia, Universidade Federal do Rio Grande do Norte, Natal, 2019. Disponível em: < http://monografias.ufrn.br/handle/123456789/8866>.

Cuba, M. A. (2010). Educação Ambiental nas escolas. Revista de Educação, Cultura e Comunicação, (1) 2, 23-31.

Da Silva, F. S.; Terán, A. F. (2018). Práticas pedagógicas na educação ambiental com estudantes do ensino fundamental. Experiências em Ensino de Ciências. Manaus - AM, (13) 5, 339351.

De Oliveira, E. M.; Palheta, G. S; Seabra, L. B. (2017). O Ensino de Ciências e Energias Renováveis: proposta metodológica do forno solar. Ciência e Natura, (39) 1, 99-107.

Effting, T.F. (2007). Educação ambiental nas escolas públicas: realidade e desafios. Monografia, Universidade Estadual do Oeste do Paraná, Marachel Cândido Rondon (PR), 2007. 90p. Monografia (Pós Graduação em "LatuSensu" Planejamento Para o Desenvolvimento Sustentável) - Centro de Ciências Agrárias, Universidade Estadual do Oeste do Paraná - Campus de Marechal Cândido Rondon.

Fragoso, E.; Nascimento, E. C. M. (2018). A Educação Ambiental no Ensino e na Prática Escolar da Escola Estadual Cândido Mariano-Aquidauana/MS. Ambiente \& EducaçãoRevista de Educação Ambiental, (23) 1, 161-184. Disponível em: < DOI: https://doi.org/10.14295/ambeduc.v23i1.6988 >. Acesso em: 05 de fev. 2020.

Gallego, R. C.; et al. (2014). A utilização do forno solar como instrumento de investigação na educação ambiental. REMEA - Revista Eletrônica do Mestrado em Educação Ambiental, [S.1.], 189-200, maio. Disponível em: <doi:https://doi.org/10.14295/remea.v0i0.4444>.

Gil, A. C. (2010). Métodos e Técnicas de Pesquisa Social. (6. ed.). São Paulo: Atlas.

Gonçalves, A, F, L.; Schuck, M, A.; Senne, S, C.; Trindade, T, V. (2017). A educação ambiental em escolas municipais: um estudo de caso na escola municipal Cei Ritta Anna de Cássia. Memorial TCC Caderno da Graduação, (3) 1, 481-499.

Kondrat, H. Maciel, M. D. (2013). Educação ambiental para a escola básica: contribuições para o desenvolvimento da cidadania e da sustentabilidade. Revista Brasileira de Educação, Rio de Janeiro, (18) 55, 825-846.

Loureiro, C. F. B. (2006). Complexidade e dialética: contribuições à práxis política e emancipatória em educação ambiental. Revista Educação e Sociedade, Campinas, vol. (27) 94, 131-152.

Lopes, W.; Bispo, W.; Carvalho, J. (2009). Educação Ambiental nas Escolas: Uma estratégia de Mudança Efetiva.

Paulo, R. F. (2011). O desenvolvimento industrial e o crescimento populacional como fatores 
geradores do impacto ambiental. Veredas do Direito: Direito Ambiental e Desenvolvimento Sustentável, Belo Horizonte, (7), 13-14.

Ribeiro, W. C. (2009). Meio ambiente e educação ambiental: as percepções dos docentes do curso de geografia da PUC Minas - Unidade Coração Eucarístico. Dissertação apresentada ao Programa de Pós-Graduação em Educação e aprovada em 26 de fevereiro de 2009. Belo Horizonte/MG.

Sarmento, J. S. (2015). Construção e análise de um forno solar como uma atividade prática não formal no ensino de física. 2015. 76 f. Dissertação de mestrado - Universidade Federal do Ceará, Centro de Ciências e Matemática, Fortaleza, 2015. Área de concentração: Ensino de Ciências e Matemática.

Sartori, S.; Latronico, F.; Campos, L. M. S. (2014). Sustentabilidade e desenvolvimento sustentável: uma taxonomia no campo da literatura. Ambiente \& sociedade, online, (17) 1, 01-22.

Sato, M. (1997). Educação para o ambiente amazônico. 245p., il. Tese (Doutorado) Universidade Federal de São Carlos. Disponível em: http://www.lapa.ufscar.br/pdf/tese_doutorado_michele_sato.pdf. Acesso em: 29/08/2019.

Silva, N. F. da; Ruffino, P. H. P. (2016). Educação ambiental crítica para a conservação da biodiversidade da fauna silvestre: uma ação participativa junto ao Projeto Flor da Idade, Flor da Cidade (Itirapina-São Paulo). Revista Brasileira de Estudos Pedagógicos, Brasília, (97) 247, 637-656.

Silva, D. et al. (2016). A importância da sustentabilidade para a sobrevivência das empresas. Empreendedorismo, Gestão e Negócios, Pirassununga, SP, (5) 5, 74-79.

Silva, E. M. C. (2010). A Educação Ambiental no Contexto da Educação Infantil. Programa de Pós-Graduação, Universidade Cândido Mendes. Pontalina.

Tozoni, M. F. C. R. (2006). Temas ambientais como "temas geradores": contribuições para uma metodologia educativa ambiental crítica, transformadora e emancipatória. Revista Educar, Curitiba, (27), 93-110. 